\title{
A Compreensão Oral em Softwares Didáticos DE Língua Italana como Língua Estrangeira Avaliação e Design de Atividades
}

\author{
Ròmulo Francisco De Souza*
}

RESUMO: Apresenta-se parte dos resultados de uma pesquisa cujo objetivo foi avaliar softwares de autoaprendizagem do italiano como língua estrangeira, tendo por foco de avaliação as técnicas disponibilizadas para o ensino da compreensão oral (CO). Em linhas gerais, analisa-se se os softwares que compõem o corpus oferecem meios para que, com o seu auxílio, o aprendiz consiga aprender a língua italiana para comunicação em interações face a face. Opta-se pela habilidade de $\mathrm{CO}$ por esta ser condição indispensável para o sucesso em interações dessa natureza. Adotase, como instrumento de avaliação, uma lista de checagem cujos itens apontam para características consideradas essenciais em materiais didáticos desenvolvidos para o ensino de CO. Apresentam-se os resultados que abrangem a questão da organização dos percursos didáticos de $\mathrm{CO}$ nas fases de pré-escuta, escuta e pósescuta, e conclui-se que, dentre os softwares que compõem o corpus, apenas um organiza seus percursos didáticos de $\mathrm{CO}$ em atividades dispostas segundo cada uma dessas etapas.

PALAVRAS-CHAVE: compreensão oral; língua italiana; software didático; avaliação; design.

*Doutor em Letras na área de Língua, Literatura e Cultura Italianas pela Universidade de São Paulo. 
ABSTRACT: Viene presentata in quest'articolo una parte dei risultati di una ricerca il cui obiettivo è stato valutare alcuni software per l'autoapprendimento dell'italiano come lingua straniera, concentrandosi sulla valutazione delle tecniche messe a disposizione per l'insegnamento della comprensione orale $(\mathrm{CO})$. In generale, si $\grave{e}$ analizzato se $i$ software che compongono il corpus offrono strumenti che, con il loro aiuto, possono permettere all'apprendente di imparare la lingua italiana per la comunicazione in interazioni faccia a faccia. Si è scelta l'abilità di CO visto che si tratta di una condizione indispensabile per il successo in interazioni di questa natura. Si è adottato come strumento di valutazione una lista de controllo composta da voci che si riferiscono alle caratteristiche considerate essenziali in materiali didattici sviluppati per l'insegnamento della CO. Vengono presentati i risultati che riguardano la questione dell'organizzazione dei percorsi didattici della CO nelle fasi di preascolto, ascolto e post- ascolto e si è concluso che, tra i software che compongono il corpus, solo uno organizza i suoi percorsi didattici di CO in attività disposte a seconda di queste fasi.

PAROLE CHIAVE: comprensione orale; lingua italiana; software didattico; valutazione; design.

ABSTRACT: This paper presents partial results of a research which has evaluated self-learning software programs of Italian as a foreign language, focusing on the evaluation of the techniques available for teaching listening skills (LS). It analyzes whether the programs which comprise the corpus provide learners with effective means to learn the Italian language for face-to-face interactions. The LS skill was chosen because it is a sine qua non condition for success in such interactions. The ad hoc evaluation tool was a checklist whose items address characteristics considered essential for didactic materials developed for teaching LS. The results presented entail the issue of the organization of the listening instructional pathways during the phases of pre-listening, listening and post-listening. It concludes that only one 
out of the programs that comprise the corpus organizes its instructional pathways of teaching of LS based on activities of pre-listening, listening and post-listening. KEYWORDS: listening skill; Italian language; teaching software; evaluation; design. 


\section{Introdução}

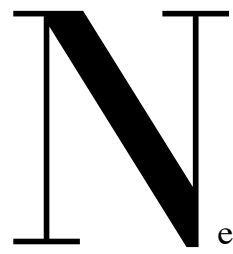

este artigo, revisitamos nossa pesquisa de mestrado, cujo objetivo foi, em linhas gerais, avaliar softwares de autoaprendizagem de língua italiana como língua estrangeira, tendo por foco de avaliação as técnicas disponibilizadas para o ensino da compreensão oral (doravante, $\mathrm{CO}$ ).

Essas técnicas, informatizadas nos quatro softwares que formaram o corpus da pesquisa - a saber: os cursos de língua italiana Q-express: italiano; Dentro l'italiano; Talk to me: italiano; e Italicon: corso di italiano per stranieri -, foram avaliadas a partir de uma lista de checagem cujos itens apontam características que consideramos necessárias a um software que tem por objetivo ensinar a compreensão de textos orais em situações de interação face a face. 
Ademais, tivemos como objetivo constatar se os referidos softwares de fato oferecem meios para que os aprendizes consigam aprender a língua italiana para comunicação, conforme anunciado em seus descritores ou títulos. Tomemos, como exemplo, o curso de Italiano Talk to me: italiano, cujo descritor, apresentado no Quadro 1, anuncia que o aprendiz será capaz de, com o seu auxílio, "entender e ser entendido em uma língua estrangeira" e "adquirir segurança na oralidade".

Quadro 1: Descritivo do software Talk to me: italiano

Talk to me é a solução para quem quer entender e ser entendido em uma língua estrangeira. A melhor maneira de aprender a falar uma língua é imergir-se em situações da vida cotidiana: Talk to Me propõe vídeos e diálogos interativos sobre temáticas da vida de todos os dias. Os vídeos e diálogos são baseados na tecnologia de reconhecimento vocal desenvolvida pela Auralog e permitem que o estudante adquira segurança na oralidade.

Fonte: TALK TO ME: ITALIANO, s.d.

Focalizamos nossas atenções na compreensão oral, já que essa habilidade é condição sine qua non para que um indivíduo participe, com sucesso, de uma conversa em linguagem oral (ROST, 1994). Em termos específicos, as perguntas que orientaram a pesquisa foram:

1. Quais técnicas de ensino relativas à $\mathrm{CO}$ estão disponibilizadas no software?

2. As atividades de CO são específicas ou estão integradas a outras atividades?

3. Os itens da lista de checagem estão contemplados? Se sim, quais? Em que medida?

4. Considerando os itens da lista de checagem, podem ser sugeridas modificações? Quais?

Mantemos, neste artigo, a lógica de trabalho estabelecida a partir dessas questões. Fazemos, 
no entanto, um recorte da pesquisa, apresentando apenas um dos aspectos explorados em nossa dissertação (SOUZA, 2007). De fato, trouxemos para debate as análises relativas aos itens 2 a 5 de nossa lista de checagem - reproduzidos no Quadro 2 -, que apontam para a questão da organização dos percursos didáticos de compreensão oral nas fases de pré-escuta, escuta e pós-escuta proposta por Underwood (1994).

Quadro 2: Itens 2 a 5 da lista de checagem: pré-escuta, escuta e pós-escuta

2. As atividades são estruturadas em pré-escuta, escuta e pós escuta?

3. Se presentes, as atividades de pré-escuta visam ativar esquemas e/ou antecipar elementos do texto relacionados ao texto-alvo (aspectos culturais, tema, participantes, estruturas ou funções linguísticas)?

4. Se presentes, as atividades de escuta visam guiar o aluno na compreensão do texto, ao invés de testar a sua compreensão?

5. Se presentes, as atividades de pós-escuta visam checar a compreensão dos estudantes, levantar, repetir e explicar os pontos problemáticos do texto e/ou ampliar conhecimentos sobre elementos da língua-alvo?

Fonte: SOUZA, 2007.

\section{A natureza da compreensão oral}

Nesta seção será discutida a noção de CO que baliza tanto as análises quanto as propostas de sequências didáticas apresentadas neste artigo.

Acreditamos que só faz sentido pensar em $\mathrm{CO}$ se for atrelada a situações comunicativas. É importante salientar que a própria $\mathrm{CO}$ pode e deve ser vista como elemento-chave para que haja comunicação verbal. De fato, não é possível ao ser humano interagir por meio oral se o mesmo não tiver a capacidade de compreender o que está ouvindo. Essa habilidade é parte da oralidade (ROST, 1994).

Não se está ignorando, com isso, o fato de que a $\mathrm{CO}$ depende da percepção material dos sons e do processamento cognitivo desse insumo material (ANDERSON e LYNCH, 1988; UNDERWOOD, 1994; BROWN, 2001; MATLIN, 2004). Tampouco se está restringindo a tarefa da $\mathrm{CO}$ ao canal auditivo, visto que a tentativa de comunicação falada se dá, também, por expressões faciais, movimentos do corpo e das mãos etc. (WIDDOWSON, 1991). Dessa 
maneira, o canal visual aparece como um meio complementar da comunicação oral e, portanto, da CO. Faz-se, aqui, aceno à CO como processo de natureza multimodal, ou seja, que envolve mais de uma modalidade perceptual (MESKILL, 1996).

A CO envolve processos sociais e cognitivos. Está ligada à forma com que o ouvinte se relaciona com as pessoas e como ele organiza seu conhecimento interno (ROST, op. cit.). Trata-se de um processo ativo (ANDERSON e LYNCH, 1988; ROST, 1994; UNDERWOOD, 1994; MESKILL, 1996; MATLIN, 2004; SADIGH e ZARE, 2006; NOBLITT, [s.d.]), de natureza interativa (BROWN, 2001) e interpretativa, em que o ouvinte constrói o significado do texto oral com o qual está interagindo (ANDERSON e LYNCH, 1988; UNDERWOOD, 1994; MATLIN, 2004; SADIGHI e ZARE, 2006).

Para Anderson e Lynch (1988), a compreensão de um texto oral consiste na interpretação coerente ou na construção de um modelo mental da mensagem sonora ouvida. Os autores explicam que o ouvinte constrói a sua própria versão do que ouve - daí a utilização do termo "interpretação" -, e essa interpretação tem que ser coerente com o que ele acredita ter sido falado e com o que ele sabe sobre o falante, sobre o contexto e sobre o mundo - por isso, a utilização do termo "coerente". Underwood (1994), em consonância com Anderson e Lynch (1988), ressalta que o significado construído pelo ouvinte pode ou não corresponder ao significado pretendido pelo falante. Essa constatação justifica a natureza interpretativa atribuída à CO.

A construção do sentido, por parte do ouvinte, ocorre a partir de processos cognitivos denominados interativos, ou seja, que associam a atuação de processamentos ascendentes (bottom-up) e descendentes (top-down) (KLEIMAN, 2002 apud EIRAS, 2004; MATLIN, 2004). Dessa forma, para obter sucesso na construção de sentidos dos textos orais com os quais interage, o ouvinte combinará informações ou pistas extraídas do texto-alvo com o seu conhecimento de mundo, com suas experiências prévias e com o contexto (ANDERSON e LYNCH, 1988; UNDERWOOD, 1994; MATLIN, 2004). A Figura 1 representa a natureza da compreensão oral conforme debatida neste artigo. 
Figura 1: Natureza da compreensão oral

\section{Natureza da compreensão oral}

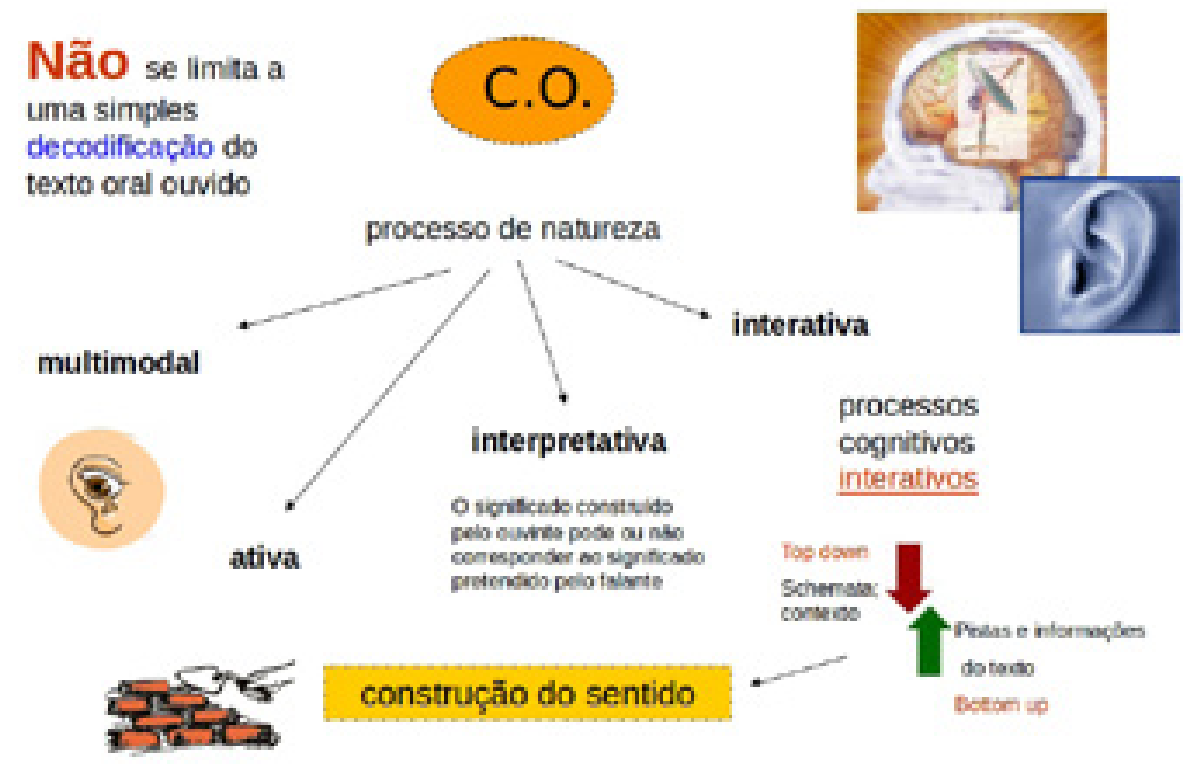

Fonte: SOUZA, 2009.

\subsection{O papel da schemata na construção do sentido}

Underwood (1994) enfatiza que o ouvinte somente conseguirá construir significado se conseguir contextualizar o que está ouvindo. Baseando-se em Widdowson (1991), a autora explica ainda que o conhecimento de mundo - conhecimento prévio, ou anterior - utilizado na construção do significado por parte do ouvinte constitui-se do conhecimento sistêmico e do conhecimento esquemático. O conhecimento sistêmico ou linguístico consiste no conhecimento a respeito dos aspectos semânticos, sintáticos e fonológicos do sistema linguístico. O conhecimento esquemático, ou não linguístico, por sua vez, constitui-se do conhecimento de tipo factual e sociocultural e do conhecimento procedimental, ou seja, o conhecimento de como a língua é utilizada no discurso. 
Sadighi e Zare (2006) também fazem referência ao papel fundamental da schemata no processamento de linguagem. Eles lembram que pesquisas em leitura sustentam a ideia de que a ativação de conhecimento prévio e sua posterior aplicação ao novo insumo facilita sensivelmente o seu processamento e sua compreensão (GRAVES e COOK, 1980; HAYES e TIERNEY, 1982; STEVENS, 1982 apud SADIGHI e ZARE, 2006; CHRISTEN e MURPHY, 1991). Os autores não hesitam em afirmar que "a ativação do conhecimento sobre o mundo claramente apoia o processamento de língua falada" (SADIGHI e ZARE, 2006, p. 112).

Matlin (2004) define os esquemas como o conhecimento generalizado sobre uma situação ou evento e explica que eles têm a função de guiar o indivíduo na compreensão de novos eventos, formando expectativas sobre o que deveria ocorrer. Citando Markman (1999) e Shoben (1988), essa autora lembra que os esquemas são usados para explicar como as pessoas processam situações e eventos complexos, entre os quais estaria a compreensão de linguagem oral. Nesse sentido, Brown e Yule (1983), concordando com Matlin, definem schemata como "o conhecimento anterior organizado que nos leva a esperar ou predizer aspectos de nossa interpretação do discurso" (p. 112). Para eles, o conhecimento do ouvinte predispõe a construção de expectativas em termos de sete fatores: o falante, o ouvinte, o lugar, o tempo, o gênero, o tópico e o co-texto. Para relacionar as informações novas e os seus conhecimentos prévios, os ouvintes se utilizam de dois princípios: o princípio da analogia - as coisas serão como elas eram antes - e o princípio da mudança mínima - as coisas são o máximo possível como elas eram antes (BROWN e YULE, 1983).

Além de se coadunarem com a ideia da construção do significado pelo ouvinte - tentando explicar como ele se beneficia de seus conhecimentos prévios durante essa tarefa-, acreditamos que os conceitos de Brown e Yule (1983) também podem ser utilizados para explicar como o ouvinte supera alguns problemas ligados à compreensão que poderiam decorrer da natureza incompleta do discurso oral, em contextos de interação face a face.

Um bom exemplo é a utilização da schemata como base de inferência para cobrir falhas ou buracos (sons, palavras ou frases não escutadas) no discurso do falante, causados por ruídos de fundo, por exemplo, que poderiam ser causa de não compreensão se o ouvinte não pudesse lançar mão desse recurso.

Sabe-se que o discurso oral é caracterizado por falsos começos, palavras reduzidas, sotaques diferentes etc. Mais uma vez, os conhecimentos prévios do ouvinte - entre outros elementos - podem servir como base para que ele construa as inferências necessárias para construir um 
significado plausível, superando vacilações. Nesse sentido, Noblitt ([s.d.]), referindo-se ao aspecto sonoro da linguagem, lembra que "longe de ser uma habilidade passiva, a compreensão oral requer a criação ativa de mensagens (entenda-se: significado) plausíveis a partir, às vezes, de insumo acusticamente incompleto" (p. 2). O autor atribui a possibilidade de lidar com esse tipo de problema ao contexto do evento de fala, ao conhecimento compartilhado pelos falantes nativos e à capacidade humana de realizar o que ele, baseado em Clark e Clark (1977), chama de análise pela síntese, que "se refere à estratégia de geração interna ou 'sombreamento' do que as pessoas dizem - ou fazem" (NOBLITT, [s.d.], p. 2). Dessa forma, explica o autor, o ser humano consegue, facilmente, predizer o próximo passo ou, ao menos, reduzir as possibilidades a serem consideradas.

\subsection{A compreensão oral: processo interativo}

A interatividade característica à CO é atribuída por Brown (2001) a dois momentos do processo: o primeiro seria a interação entre ouvinte e falante, em situações de interação face a face; o segundo seria a interação entre o cérebro e os sinais nervosos que chegam até ele carregando as informações sonoras captadas pelo ouvido. Ao chegar ao cérebro, os sinais seriam tratados através de interações com diferentes mecanismos cognitivos e afetivos. Essa interação cérebro-impulsos nervosos, que nos parece indicar, também, a natureza ativa do processo de compreensão oral, pode ser melhor compreendida face aos processamentos que, segundo Brown (2001), estariam envolvidos na compreensão de textos orais.

A primeira fase do processo, segundo esse autor, é de natureza psicomotora. Ela consiste na transformação das ondas sonoras que chegam aos ouvidos em impulsos nervosos. Esses, por sua vez, são transmitidos ao cérebro. Brown (2001), baseando-se em Clark e Clark (1977) e Richards (1983), estabelece uma série de processamentos (Quadro 3) que, segundo ele, estão envolvidos no processo de compreensão oral.

Vale ressaltar que, ainda segundo Brown (2001), exceto para o primeiro e o último processamentos citados, não há uma sequência precisa, uma vez que eles ocorrem, simultânea ou sucessivamente, em grande velocidade. Em termos neurológicos, o tempo deve ser dimensionado em termos de microssegundos.

\subsection{Forma e uso comunicativo}

Widdowson (1991) aprofunda-se na questão da compreensão oral, baseando-se na distinção 
entre forma e uso (comunicativo) da linguagem. Em situações de interação face a face, a compreensão oral é identificada como o ato de ouvir, em detrimento de escutar, e configura-se como o aspecto receptivo da ação de conversar.

A oposição entre forma e uso (comunicativo) da linguagem define a oposição entre fala e conversa, respectivamente. $\mathrm{O}$ autor define fala como "a manifestação da linguagem enquanto sistemas de formas", e a conversa como "a realização da linguagem enquanto uso na interação falada" (WIDDOWSON, 1991, p. 86). Dessa maneira, para que uma interação seja considerada uma conversa os participantes devem lidar com a sua dimensão comunicativa. Um dos elementos definidores dessa dimensão seria, exatamente, o foco na identificação e produção de frases, considerando-se, mais do que sua forma, a sua força comunicativa. Isso implica, por exemplo, a capacidade de inserir uma frase de maneira que sua força comunicativa seja coesa e coerente com o discurso que está sendo realizado naquele momento. O Quadro 3, a seguir, lista microprocessamentos inerentes a esse processo.

Quadro 3: Microprocessamentos envolvidos na compreensão oral.

O ouvinte processa o "discurso bruto" e mantém uma imagem dele na memória de curto prazo. Essas imagens consistem em: frases, orações, sentenças, marcadores coesivos, entonação, padrões de acento.

O ouvinte determina o tipo de evento de fala que está sendo processado (uma conversa, um discurso, uma propaganda de rádio etc.) e, então, "colore", apropriadamente, a interpretação da mensagem percebida.

O ouvinte infere os objetivos do falante, considerando o tipo de evento de fala, o contexto e o conteúdo. Ele determina, por exemplo, se o falante tem a intenção de persuadir, pedir, afirmar, negar, informar, e assim por diante; ou seja, a função da mensagem é inferida.

O ouvinte acessa seus conhecimentos prévios (schemata) relevantes para um determinado contexto ou assunto. Uma grande quantidade de experiências e conhecimentos é utilizada para estabelecer associações cognitivas, com o intuito de atribuir uma interpretação plausível à mensagem.

O ouvinte atribui um sentido literal à sentença. Essa atribuição envolve um conjunto de interpretações semânticas das strings superficiais que o ouvido percebeu.

O ouvinte atribui um sentido conotativo à sentença.

O ouvinte determina se a informação deve ser retida na memória de longo ou curto prazo.

Fonte: Adaptado de Brown, 2001. 
A conversa é uma ação ao mesmo tempo produtiva e receptiva, que se dá por meio dos canais auditivo e visual. $\mathrm{O}$ ato de dizer é o aspecto produtivo da conversa, e o ato de ouvir, como dito anteriormente, constitui o seu aspecto receptivo.

É importante ressaltar a utilização do canal visual como fonte de informações que ajudarão o participante da interação a construir sentido. Como dito anteriormente, gestos, expressões, movimentos do corpo são utilizados, juntamente com a fala, na tentativa de se dizer algo. Daí se considerar tanto o canal auditivo quanto o canal visual como canais para a realização da conversa. Complementarmente, é válido lembrar que também a CO (ouvir) não depende exclusivamente do canal auditivo, estando associada ao canal visual.

Ouvir significa, em última instância, reconhecer a função comunicativa, ou seja, a força comunicativa que cada frase assume em um dado discurso. Dizer significa produzir frases em meio a um discurso, considerando-se essa mesma força comunicativa.

Enquanto ouvir e dizer estão associados ao uso comunicativo, falar e escutar se relacionam com a produção material da linguagem. Falar está estritamente ligado ao meio auditivo: significa produzir frases sem que se considere sua força comunicativa.

Escutar é a "atividade de reconhecer que sinais enviados pelo meio auditivo constituem frases que têm uma dada significação" (WIDDOWSON, 1991, p. 87). Ouvir, por sua vez, como já explicado anteriormente, "é a atividade de reconhecer quais funções as frases têm numa interação, qual força comunicativa elas assumem enquanto amostras de uso" (WIDDOWSON, 1991, p. 87). Falar e escutar são atividades distintas e independentes, enquanto dizer e ouvir são aspectos de uma única atividade (a de conversar). Dizer implica, necessariamente, falar. Ouvir implica, necessariamente, escutar. O contrário não é verdade.

Ora, para que a intenção comunicativa seja identificada pelo participante de uma interação, é necessário que esse participante reconheça a materialidade da língua. A dimensão comunicativa da língua depende dessa materialidade.

A CO não se resume, portanto, a um mero exercício de decodificação da língua como código (SADIGHI e ZARE, 2006). Não se trata de um exercício de identificação plena de cada som e significado de cada palavra, fonema, ou outra unidade constituinte do texto-alvo. Anderson e Lynch (1988) apresentam um contraexemplo bastante elucidativo a respeito da natureza da CO: trata-se de uma concepção em que o ouvinte seria comparado a um gravador. Essa analogia sugere que, se o insumo for suficientemente alto para ser gravado e não exceder a capacidade disponível da fita, a mensagem será gravada e armazenada, e poderá ser acessada novamente 
mais tarde. Ela está, portanto, mais associada à habilidade de recall do ouvinte, ou seja, de ele se lembrar do que ouviu, palavra por palavra.

\subsection{O paradigma do gravador}

O paradigma do ouvinte como gravador, segundo ainda Anderson \& Lynch (1988), poderia explicar as diferentes maneiras com que os ouvintes se comportam e tratam as mensagens ouvidas, da seguinte forma:

a. Falha na compreensão de mensagens longas: poderia ser explicada pelo fato de o gravador mental não ter espaço suficiente para fazer a gravação;

b. Perda ou distorção da mensagem: em condições não ideais de escuta, o gravador mental poderia não ter sido capaz de fazer gravações claras;

c. A fita - e, consequentemente, a mensagem - poderia se deteriorar após um longo período entre a gravação e o acesso a ela; e

d. Diferenças individuais entre ouvintes: um ouvinte estrangeiro poderia ser considerado um gravador de baixa qualidade, o qual funcionaria bem somente sob condições ideais de escuta/gravação - mesmo assim, a gravação seria distorcida na execução. O oposto seria o ouvinte nativo adulto.

A analogia com o gravador, porém, não explica todas as características relevantes da compreensão, como discutido anteriormente. Anderson \& Lynch (1988) lembram que compreender não implica, necessariamente, lembrar-se do que foi dito: pode-se memorizar a mensagem inteira, sem tê-la compreendido; da mesma forma, pode-se entender uma mensagem oral e não se lembrar exatamente de como ela foi dita, mesmo em língua materna. $\mathrm{O}$ fato de um estrangeiro, por exemplo, conseguir montar uma tomada em um sistema inglês a partir de instruções orais comprova que ele entendeu tais instruções. A sua habilidade de recontar as instruções, por outro lado, não comprova a sua compreensão. A diferença entre o uso de uma informação compreendida e sua repetição está no fato de que, para usar uma informação, “o ouvinte normalmente tem que interpretar o que foi dito e relacionar isso com o ambiente não 
linguístico" (ANDERSON e LYNCH, 1988, p. 10), o que envolve algum tipo de processamento ativo do insumo. $\mathrm{O}$ fato de repetir o que foi dito não envolve tal tipo de processamento. Os autores lembram que mesmo situações de $\mathrm{CO}$ que requerem recall normalmente envolvem algum tipo de processamento do insumo.

Acreditamos termos apresentado, nesta seção, uma discussão suficientemente clara sobre a natureza da $\mathrm{CO}$ que justifica a necessidade de se pensar em práticas pedagógicas que a pressuponham como um processo complexo (MESKILL, 1996) e central na comunicação oral.

\section{Ensino de compreensão oral: atividades de pré-escuta, escuta e pós-escuta}

Underwood (1994) propõe que uma atividade de CO seja organizada em três estágios: a pré-escuta, a escuta e a pós-escuta. Para sugerir tal divisão, a autora se baseia na noção de que a $\mathrm{CO}$ consiste em um processo complexo, de natureza interativa e construtiva, conforme discutido na seção anterior.

Além disso, ela parte da ideia de que uma atividade de $\mathrm{CO}$ deve oferecer ao aluno oportunidade para que ele utilize sua habilidade natural de $\mathrm{CO}$, ou seja, da mesma maneira que ele deverá usar em situações reais. Capra (2005), ao discutir esse mesmo framework, ressalta a contribuição fundamental de Underwood (1994) para a evolução da didática da CO.

Em harmonia com Capra (2005), concordamos com os pontos de vista dessa autora e, por isso, adotamos esse framework como referência para a estruturação de atividades e sequências didáticas de CO.

A etapa de pré-escuta, como o próprio nome indica, é composta por atividade(s) executada(s) antes do contato com o texto-alvo oral. Seu objetivo é ativar ou fornecer conhecimentos sobre esse texto, antecipando informações referentes ao tema, aos participantes, a aspectos culturais e, também, antecipando vocabulário e elementos de sintaxe. Essa etapa tornará a experiência de $\mathrm{CO}$, proposta na atividade, mais próxima de uma experiência real, na medida em que dará ao ouvinte suporte para que consiga utilizar habilidades que, normalmente, utiliza em situações de $\mathrm{CO}$ em sua língua materna. Segundo a autora, muito raramente o ouvinte confronta um texto oral sem ter expectativas sobre o que vai ouvir, e vale lembrar que tais expectativas serão comparadas pelo ouvinte com as informações novas advindas do texto. Essa estratégia o ajudará na tarefa de construir sentido a partir daquele texto. 
A etapa da escuta contém atividades que serão desenvolvidas exatamente durante a escuta do texto-alvo. O seu objetivo é, mais uma vez, ajudar o aprendiz não nativo a aprender a aplicar as habilidades utilizadas na $\mathrm{CO}$, ou seja, aquelas que ele já tem e usa quando ouve em língua materna. A autora lembra que o intuito é guiar o aluno pelo texto, auxiliá-lo no desenvolvimento de suas habilidades para construir sentido a partir da língua falada, e não submetê-lo a testes de compreensão oral.

Em suas explicações sobre a etapa de escuta, Underwood (1994) focaliza como habilidades necessárias para a $\mathrm{CO}$ - e que, portanto, merecem ser praticadas nas atividades feitas durante a escuta - apenas a predição (micro), a comparação (de informação nova e expectativas) e a interpretação. A autora explica que, durante a escuta do texto, o ouvinte, simultaneamente, faz microprevisões - ou seja, prevê quais palavras ou ideias seguirão imediatamente ao que acaba de ouvir -; faz comparações entre o que acaba de ouvir e o que havia previsto; e faz interpretações das informações novas que está ouvindo, o que gera novas expectativas.

Enfim, a etapa de pós-escuta é realizada depois das atividades feitas durante a escuta. Seus objetivos são checar a compreensão dos estudantes; levantar, repetir e explicar os pontos problemáticos do texto (ou seja, que tenham prejudicado a compreensão dos aprendizes e que, por isso, não tenham ficado claros para eles); dar aos aprendizes oportunidade para reverem o comportamento e as atitudes dos participantes do texto oral; e dar-lhes oportunidade de se colocarem em relação ao texto, ou seja, de expressarem sua opinião.

Buscando a melhor compreensão do perfil das atividades de cada etapa, reunimos, no Quadro 4, apresentado a seguir, algumas sugestões de atividades que, de acordo com Underwood (1994), poderiam ser utilizadas nos estágios de pré-escuta, escuta e pós-escuta. 
Quadro 4: Atividades de pré-escuta, escuta e pós-escuta

\begin{tabular}{|c|c|c|}
\hline Pré-escuta & Escuta & Pós-escuta \\
\hline Observar imagens; & $\begin{array}{l}\text { Introduzir ou checar itens em } \\
\text { imagens; }\end{array}$ & Role-play; \\
\hline Ler um texto introdutivo; & Identificar imagens; & $\begin{array}{l}\text { Trabalhos escritos: resumos, } \\
\text { respostas escritas; }\end{array}$ \\
\hline $\begin{array}{l}\text { Ler perguntas de um questionário } \\
\text { (que serão respondidas enquanto } \\
\text { se escuta o texto); }\end{array}$ & $\begin{array}{l}\text { Escolher as imagens que indicam } \\
\text { a sequência certa de uma história; }\end{array}$ & Preenchimento de formulários; \\
\hline $\begin{array}{l}\text { Levantar listas de itens, } \\
\text { pensamentos, ideias, sugestões } \\
\text { etc.; }\end{array}$ & $\begin{array}{l}\text { Colocar imagens em ordem; } \\
\text { Desenhar; }\end{array}$ & $\begin{array}{l}\text { Jigsaw; } \\
\text { Atividades de problem-solving e } \\
\text { decision-making; }\end{array}$ \\
\hline $\begin{array}{l}\text { Etiquetar desenhos } \\
\text { ou parágrafos com títulos ou } \\
\text { termos; }\end{array}$ & $\begin{array}{l}\text { Cumprir ações; } \\
\text { Seguir ou traçar uma rota; }\end{array}$ & $\begin{array}{l}\text { Estabelecimento do modo, } \\
\text { atitude e comportamento dos } \\
\text { interlocutores do texto; }\end{array}$ \\
\hline Completar um gráfico; & $\begin{array}{l}\text { Completar gráficos, tabelas ou } \\
\text { formulários; }\end{array}$ & $\begin{array}{l}\text { Identificação da relação entre os } \\
\text { interlocutores do texto; }\end{array}$ \\
\hline Formular previsões ou hipóteses; & & \\
\hline $\begin{array}{l}\text { Prever a linguagem que será } \\
\text { ouvida no texto; }\end{array}$ & $\begin{array}{l}\text { Marcar como verdadeiro ou falso; } \\
\text { Etiquetar desenhos ou parágrafos } \\
\text { com títulos ou termos; }\end{array}$ & Entre outras. \\
\hline $\begin{array}{l}\text { Debater informalmente em } \\
\text { grupo; }\end{array}$ & Completar espaços; & \\
\hline Entre outras. & Entre outras. & \\
\hline
\end{tabular}

Fonte: Adaptado de Underwood, 1994. 


\section{Metodologia de pesquisa}

Em nossa pesquisa identificamos, descrevemos e avaliamos as técnicas relativas à compreensão oral, disponibilizadas nos softwares que compõem o nosso corpus. Utilizamos como instrumento de avaliação uma lista de checagem, de nossa autoria, cujos itens apontam para características que consideramos essenciais em materiais informatizados para o ensino de $\mathrm{CO}$ visando à comunicação. A lista de checagem completa pode ser vista no Apêndice A.

Nas seções seguintes apresentaremos os resultados de nossa avaliação no que diz respeito aos itens 2 a 5 da lista de checagem. Como anunciado na introdução deste artigo, trata-se dos itens que apontam para a questão da organização dos percursos didáticos de compreensão oral nas fases de pré-escuta, escuta e pós-escuta, proposta por Underwood (1994).

\section{Resultados da avaliação}

Dentre os softwares avaliados - a saber: os cursos de língua italiana $Q$-express: italiano; Dentro l'italiano; Talk to me: italiano; e Italicon: corso di italiano per stranieri -, o curso Italicon é o único que organiza suas atividades de $\mathrm{CO}$ em pré-escuta, escuta e pós-escuta. Ressalta-se que em todas as fases cumprem-se papéis característicos, como discutido na seção 3.

Nas seções subsequentes apresentaremos e discutiremos nossa avaliação a esse respeito. Apresentaremos, ainda, nossas conclusões e propostas de percursos didáticos. Os comentários estão focalizados apenas no curso Italicon.

\subsection{Da estruturação da atividade de CO em pré-escuta, escuta e pós-escuta}

A atividade de pré-escuta do módulo ASCOLTO do curso Italicon cumpre o seu papel na medida em que antecipa, claramente, o tema do texto-alvo. Ela apresenta quatro textos sobre a questão da doação de sangue. De fato, esse é o tema do texto-base da unidade.

Os textos dos exercícios são apresentados fora de ordem, e cada texto pertence a um exercício: a tarefa do aluno é reorganizá-los. A Figura 2 mostra uma parte de um desses exercícios. 
Figura 2: Italicon: atividade de pré-escuta

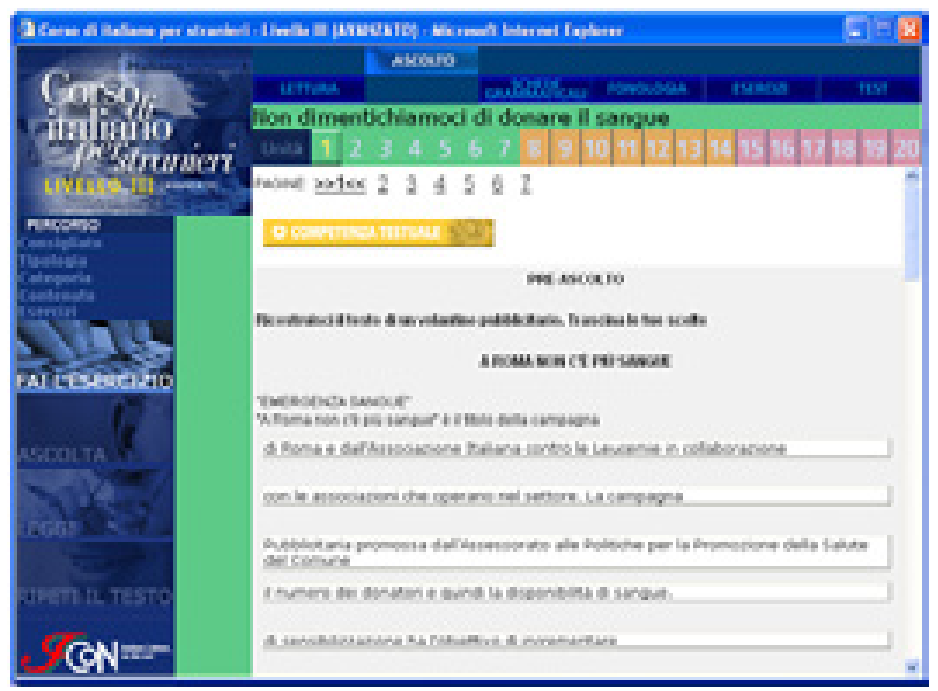

Fonte: Arquivo do autor.

Ainda sobre a atividade de pré-escuta, notamos que os autores não mantiveram os traços visuais que caracterizam o gênero dos textos escolhidos para a atividade de pré-escuta. Trata-se de textos tirados de panfletos. Como mostra a Figura 2, os textos foram reformatados.

A atividade de escuta, ainda do módulo ASCOLTO do curso Italicon, também cumpre o seu papel de atividade de audição. Ela é composta de três exercícios que demonstram uma tentativa de guiar o aluno na compreensão do texto, ao invés de apenas tentar testá-la.

O primeiro exercício (Figura 3 ) tem como objetivo a escuta do texto e a resposta a questões de múltipla escolha sobre esse texto. $\mathrm{O}$ cuidado ao tentar guiar o aprendiz na compreensão do texto pode ser verificado no fato de que a cada pergunta do questionário estão associadas apenas as partes do texto em que as respostas poderão ser encontradas. Os respectivos trechos são acessíveis pelos botões ASCOLTA, que se encontram ao lado de cada questão (Figura 4). 
Figura 3: Italicon: tela 2, parte inicial da atividade de escuta

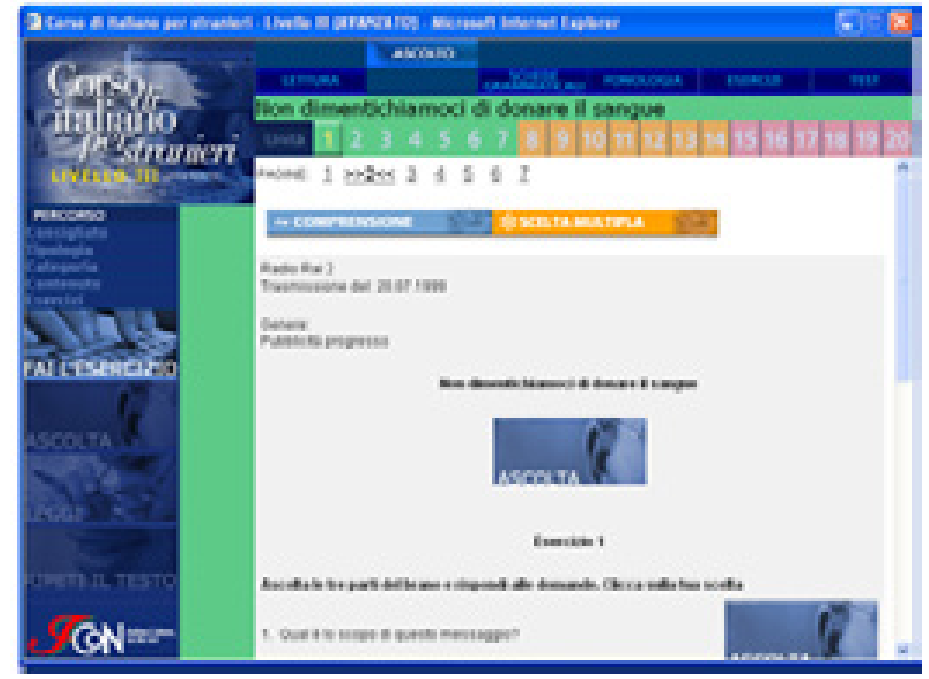

Fonte: Arquivo do autor.

Figura 4: Italicon: tela 2. parte final da atividade de escuta

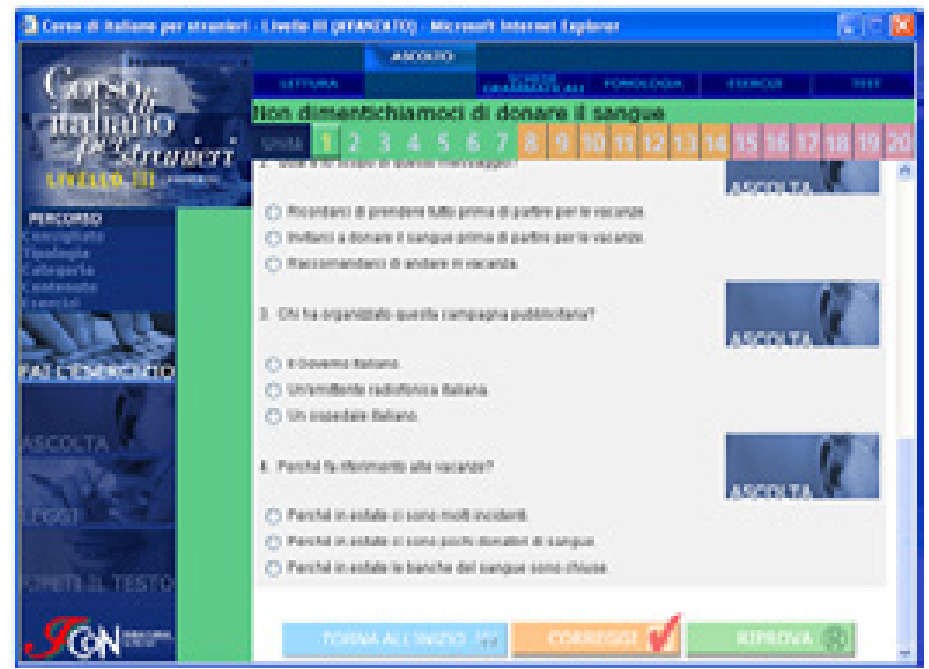

Fonte: Arquivo do autor. 
O segundo exercício propõe um preenchimento de lacunas a partir da reescuta do texto. Como podemos ver na Figura 5, não há um padrão de escolha para as palavras que devem ser preenchidas. A atividade tem como foco o reconhecimento de formas do Italiano, presentes no texto, mas também não se restringe a apenas testar se o aluno compreendeu ou não as formas. Esse cuidado está do fato de ele poder ouvir o texto quantas vezes precisar para cumprir a atividade. Notamos que, no próprio enunciado da atividade, o aluno é conscientizado sobre essa possibilidade. Na Figura 5 podemos observar a frase exata da instrução: "você pode escutar o texto quantas vezes quiser".

Figura 5: Italicon: tela 3, atividade de escuta

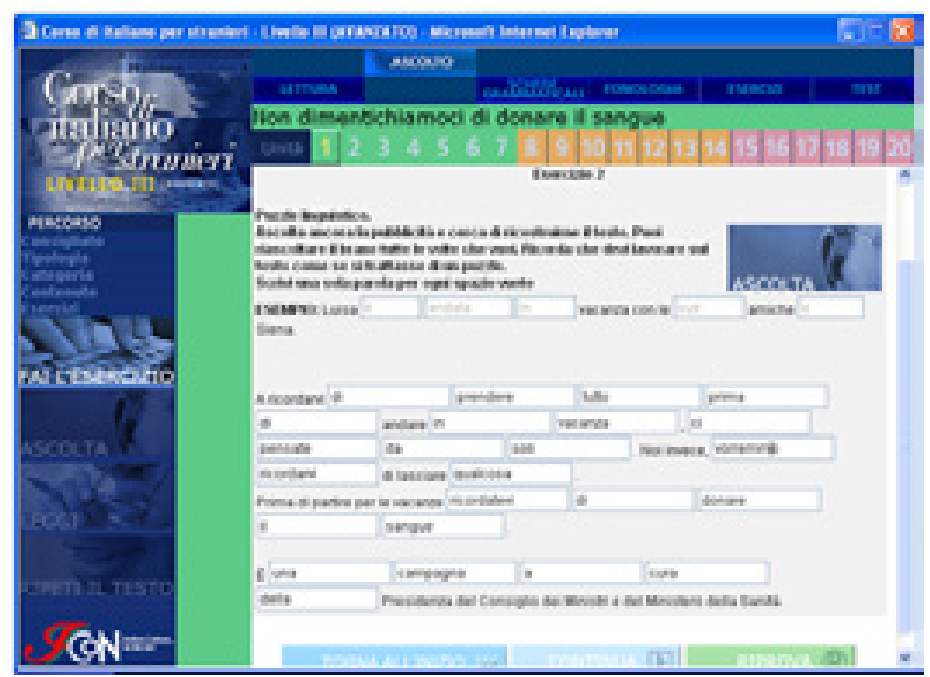

Fonte: Arquivo do autor.

O exercício 3 caracteriza-se, também, como um exercício de preenchimento de lacunas. $\mathrm{O}$ seu foco, no entanto, é o reconhecimento das formas do imperativo presentes no texto (Figura 6). Mais uma vez, vemos o botão ASCOLTA, que permite acesso irrestrito ao texto oral e marca, segundo nossa análise, uma preocupação em guiar o aluno à compreensão, e não em apenas testá-la. 
Figura 6: Italicon: atividade de escuta, preenchimento de lacunas 2

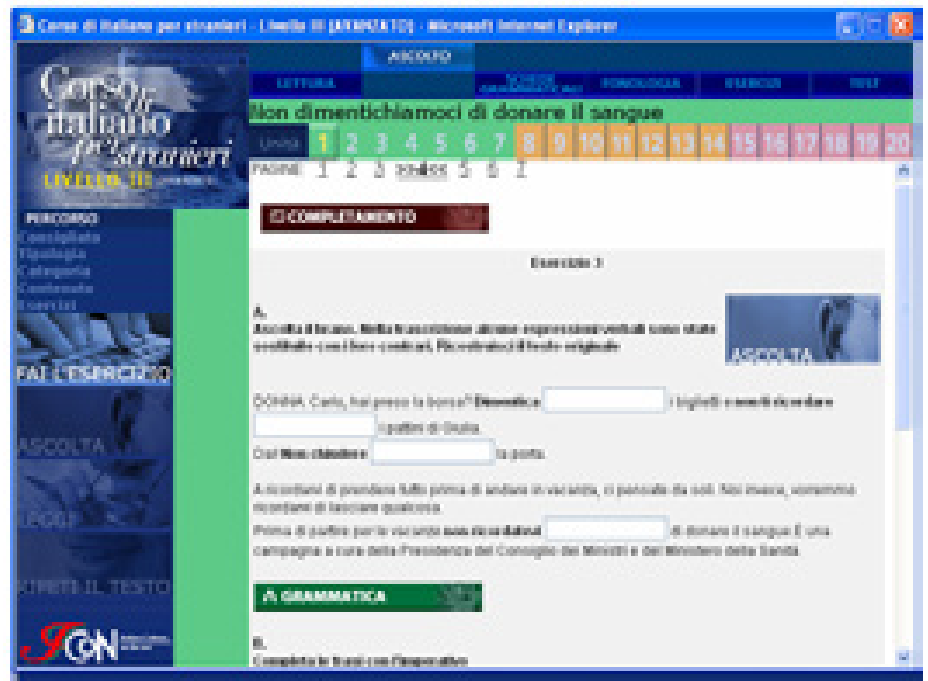

Fonte: Arquivo do autor.

Por fim, as atividades de pós-e no imperativo e acrescentando os pronomes necessários.

Figura 7: Italicon: atividade de pós-escuta

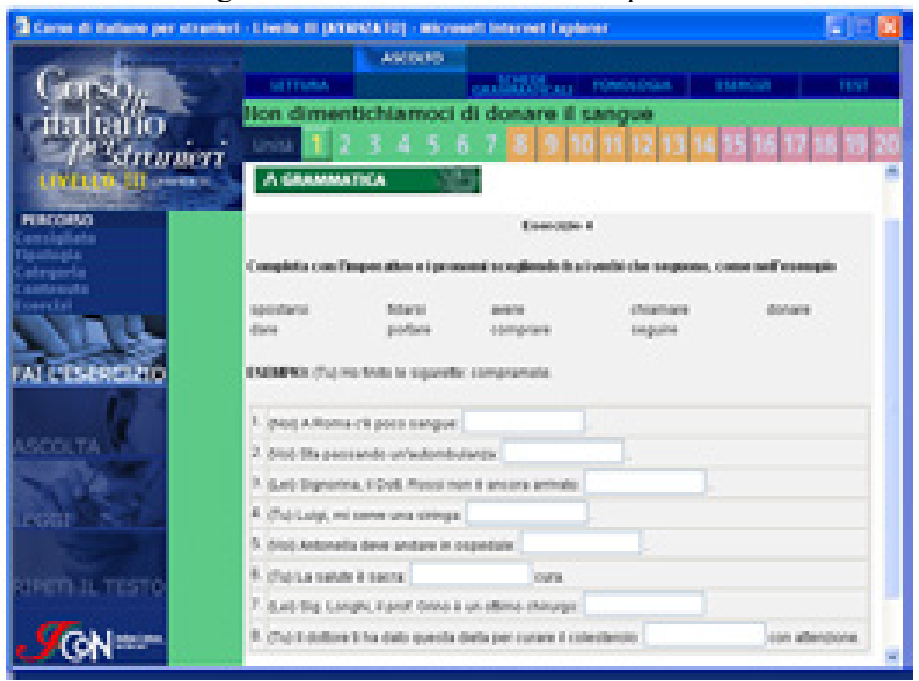

Fonte: Arquivo do autor. 


\section{Aprofundamento da análise e sugestões de design}

A organização das atividades de $\mathrm{CO}$ em pré-escuta, escuta e pós-escuta mostra preocupação em oferecer ao aprendiz oportunidade de experienciar a $\mathrm{CO}$ de maneira mais condizente com a $\mathrm{CO}$ em situações reais, incluindo situações de interação face a face, ao mesmo tempo em que considera a natureza interativa da $\mathrm{CO}$.

De fato, as atividades de pré-escuta têm como meta principal acionar os esquemas do leitor relativos ao texto-alvo, e fixar os objetivos de CO para a escuta do texto. Sabemos que em situações reais de $\mathrm{CO}$ o ouvinte constrói o significado do texto que escuta não só a partir das informações ali presentes, mas também a partir do seu conhecimento anterior. Esse ouvinte, além disso, dificilmente se aventura na empreitada da compreensão de um texto oral sem ter uma meta ou um objetivo relacionado à escuta daquele texto. Dessa maneira, durante uma conversação, por exemplo, o ouvinte poderá considerar apenas as informações que lhe interessam para cumprir seus objetivos de escuta.

Cabe às atividades de escuta oferecer ao aluno meios para aprender a explorar o texto oral com o qual está lidando e para que tenha sucesso na sua compreensão. Não é, portanto, tarefa da atividade de escuta testar a compreensão do aprendiz, mas, sim, ensiná-lo a compreender textos orais.

As atividades de pós-escuta, por sua vez, têm como meta principal rever os pontos mais problemáticos do texto escutado, conscientizando o aprendiz sobre tais pontos, e oferecer-lhe meios para expandir seus conhecimentos sobre a língua-alvo.

Gostaríamos de avaliar, portanto, como positivo o fato de a unidade de $\mathrm{CO}$ do curso que analisamos - Italicon - organizar suas atividades de $\mathrm{CO}$ em pré-escuta, escuta e pós-escuta.

Acreditamos que tal escolha auxilia no desenvolvimento da habilidade de $\mathrm{CO}$ em interações face a face, na medida em que guia o aluno em prática que lhe permitirá o desenvolvimento de habilidade que será usada em qualquer situação real de escuta, inclusive nas próprias interações face a face.

As explicações das atividades a serem realizadas durante a escuta - o que fornece objetivos de escuta para o aprendiz - poderiam ser feitas, no módulo de CO do curso Italicon, durante a pré-escuta, mas isso não acontece.

As suas atividades de pré-escuta trabalham a antecipação dos assuntos do texto, o que, de fato, estimula a ativação dos esquemas do aprendiz sobre ele. Observamos, contudo, que a 
atividade de pré-escuta não estimula o aluno à criação consciente de hipóteses sobre o texto. Acreditamos que a atividade de pré-escuta seria mais rica se cumprisse, também, essas duas tarefas: tanto a de fornecer ao aluno, com clareza, seus objetivos de escuta, e a de exercitar a formulação consciente de hipóteses sobre o texto-alvo.

A respeito dessa formulação consciente de hipóteses, sugerimos a adaptação de técnicas que consideramos tradicionais, com o cuidado de não desperdiçar os recursos que o meio informatizado disponibiliza.

A Figura 8 mostra uma sugestão de atividade de pré-escuta que apresenta elementos cujo foco é auxiliar o aluno no levantamento consciente de hipóteses sobre o texto que deverá ser ouvido a posteriori, ou seja, o texto-alvo da unidade. Utilizamos a técnica de fazer perguntas abertas ao aluno sobre temas relacionados ao texto-alvo, de modo a acionar sua schemata, sendo que uma delas contextualiza o texto e pergunta diretamente ao aluno o que ele espera ouvir.

O texto-alvo, intitulado I diritti di tutti ${ }^{1}$ consiste em um diálogo em que Monica relata a Dario sua experiência de se deslocar em uma cidade turística italiana, acompanhando um amigo, portador de necessidades especiais, que precisa de uma cadeira de rodas para se locomover.

Durante o diálogo, ela aponta as dificuldades pelas quais passou, e ambos expõem suas opiniões sobre a questão da adaptação das cidades para esse tipo de demanda, ou seja, para a facilitação da locomoção de cadeirantes e demais portadores de necessidades especiais.

1 Elaboramos esta atividade a partir do texto I diritti di tutti, disponibilizado em Leone (2004). 
Figura 8: Sugestão de atividade de pré-escuta interativa - protótipo

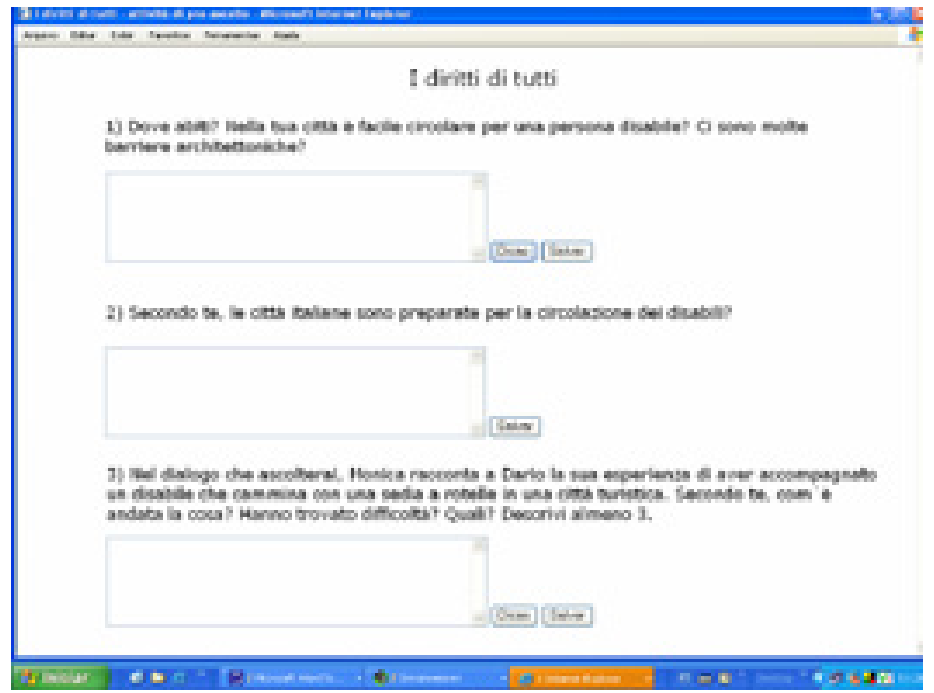

Fonte: Arquivo do autor. Adaptado de Souza (2009).

As perguntas 1 e 2 têm com objetivo principal estimular os conhecimentos prévios dos aprendizes sobre o assunto. A pergunta 3 tem por objetivo incentivar o aluno a levantar hipóteses diretas sobre o texto.

Juntamente com as perguntas 1 e 3 estão disponibilizados dois botões. O botão SALVAR, colocado também na pergunta 2 , permite que o aprendiz grave suas respostas. O botão DICAS permite que o aprendiz tenha acesso aleatório a respostas de outros aprendizes. O objetivo da função acionada pelo botão DICAS é permitir que o aluno entre em contato com o insumo produzido por outros aprendizes - ou seja, suas respostas às mesmas perguntas -, tendo como resultado a possibilidade de aquisição de vocabulário, estruturas, elementos relacionados ao tema em discussão, entre outras vantagens.

Com isso, nossa meta foi incentivar com as perguntas a ativação de conhecimentos prévios do aprendiz, e ampliar ou formar, com a função dicas, sua schemata, por meio da interação assíncrona com outros aprendizes. A Figura 9, a seguir, apresenta, em um nível mais abstrato, nossa sugestão de estratégia para promover a troca de informações entre aprendizes/usuários de softwares didáticos durante uma atividade de pré-escuta. 
Figura 9: Atividade de pré-escuta: estratégia para ambientes informatizados

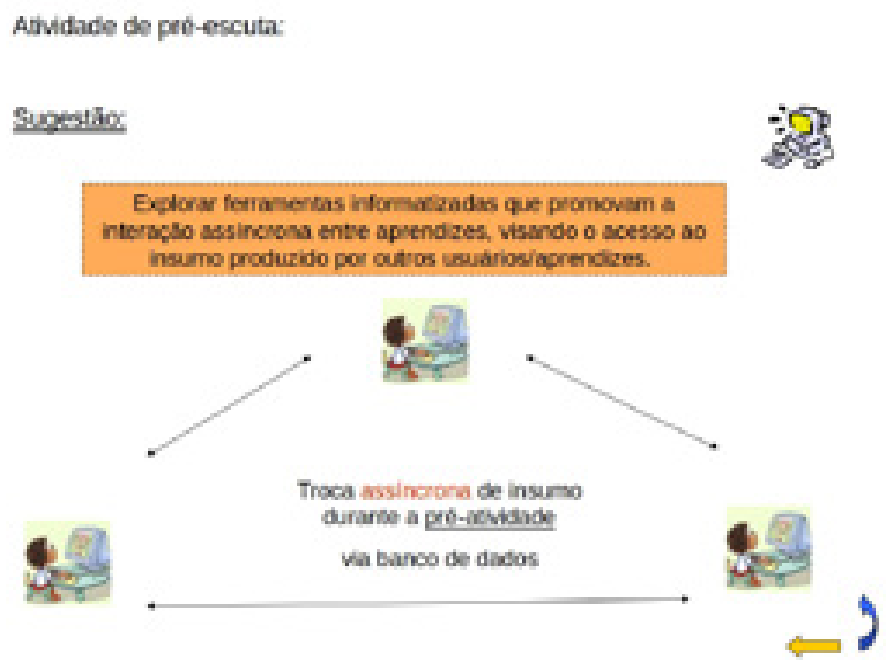

Fonte: adaptado de Souza (2009).

Consideramos que essa ampliação ou formação de schemata deverá auxiliar o aprendiz não só na compreensão do texto-alvo da unidade, mas também lhe será útil quando se deparar com textos orais em situações reais que tratarem do mesmo assunto.

Com relação, ainda, à atividade de pré-escuta do módulo de CO do curso Italicon, consideramos negativa a falta dos traços visuais do gênero panfleto a que pertencem os textos ali presentes. A nosso ver, essas características poderiam ser utilizadas, por exemplo, como elemento base para discussões sobre a noção de gênero e poderiam ainda ser expandidas para os textos orais.

Conscientes dessa noção, os aprendizes poderiam ter mais argumentos para se basearem, por exemplo, na descoberta e utilização de estratégias de $\mathrm{CO}$, em qualquer contexto.

\section{Conclusões}

Dos quatro softwares que compõem o corpus desta pesquisa - Q-express: italiano; Dentro l'italiano; Talk to me: italiano; e Italicon: corso di italiano per stranieri -, apenas o curso Italicon se preocupa em organizar suas atividades de $\mathrm{CO}$ em pré-escuta, escuta e pós-escuta. 
Avaliamos esse aspecto como positivo.

Percebemos que as atividades de pré-escuta, escuta e pós-escuta do curso Italicon são coerentes com as características de cada fase apontadas por Underwood (1994), conforme discutido nas seções 3 e 6 deste artigo.

\section{Referências}

ANDERSON, A.; LYNCH, T. Listening. Oxford: Oxford University Press, 1988.

BROWN, H. D. Teaching by Principles: An Interactive Approach to Language Pedagogy. 2.ed. New York: Longman, 2001, apud SADIGHI, F; ZARE, S. Is Listening Comprehension Influenced by the Background Knowledge of the Learners?: A Case Study of Iranian EFL Learners. In The linguistic Journal, v. 1, n. 3: 110-126, 2006.

http://www.linguistics-journal.com/November_2006_fs\&sz.php Acesso: 24/04/2007.

BROWN, G.; YULE, G. Discourse analysis. Cambridge: Cambridge University Press, 1983.

CAPRA, U. Tecnologie per l'apprendimento linguistico. Roma: Carocci, 2005.

CHRISTEN, W. L.; MURPHY, T. J. Increasing comprehension by activating prior knowledge. ERIC Digest \# 61. Bloomington, 1991. In ERIC Clearinghouse on Reading, English, and Communication. (ERIC Document Reproduction Service N. ED 328885).

CLARK, H. H.; CLARK, E. V. Psychology and Language: An introduction to Psycolinguistics. New York: Harcourt Brace Jovanovich. 1977.

DENTRO L'ITALIANO. Versão 4.0. Didael, 2007.

http://www4.didael.it/dit4/dit4_italica_07/it/set_lng.htm Acesso: 20/07/2007.

EIRAS, P. R. S. A concepção de leitura em livros de inglês instrumental: uma prática do cotidiano escolar. 2004. 86 f. Dissertação (Mestrado em Estudos Linguísticos). Belo Horizonte: Faculdade de Letras (FALE), Universidade Federal de Minas Gerais, 2004.

GRAVES, M.; COOK, C. Effects of previewing difficult short stories for high school students. In Research on Reading in Secondary Schools, 6: 38-54, 256-280, 1980.

HAYES, D.; TIERNEY, R. Developing readers' knowledge through analogy. In Reading Research Quarterly, v. 17, n. 2: 256-280, 1982.

ITALICON, corso di italiano per stranieri. Icon (Italian Culture on the Net), 2007.

http://www.italicon.it/segreteria/demoroma3light/index.htm Acesso: 20/07/2007.

KLEIMAN, A. Texto e leitor: aspectos cognitivos da leitura. 8. ed. Campinas, SP: Pontes, 2002, apud EIRAS, P. R. S. A concepção de leitura em livros de inglês instrumental: uma prática do cotidiano escolar. 
2004. 86 f. Dissertação (Mestrado em Estudos Linguísticos). Belo Horizonte: Faculdade de Letras (FALE), Universidade Federal de Minas Gerais, 2004.

LEONE, P. Attività di Ascolto. Recanati, Itália: ELI, 2004.

MARKMAN, A. B. Knowledge representation. Mahwah, NJ: Erlbaum, 1999.

MATLIN, M. W. Psicologia cognitiva. 5. ed. Trad. Stella Machado. Rio de Janeiro: LTC, 2004.

MESKILL, C. Listening Skills Development Through Multimedia. Jl. of Educational Multimedia and Hypermedia. 1996, v. 5, n. 2, p. 179-201.

http://www.cfv.org/caai/nadh166.pdf Acesso: 24/04/2007.

NOBLITT, J. S. Cognitive Approaches to Listening Comprehension. (s.d.) http://www.unc.edu/cit/ iat-archive/publications/noblitt/noblitt3.html Acesso: 20/11/2005.

Q-EXPRESS, italiano. Curitiba: Positivo Informática, (s.d.). 1 CD-ROM.

RICHARDS, J. C. Listening Comprehension: Approach, design, procedure. In TESOL Quarterly, 17: 219-239, 1983.

ROST, M. Introducing Listening. New York: Pinguin Books, 1994.

SADIGHI, F.; ZARE, S. Is Listening Comprehension Influenced by the Background Knowledge of the Learners?: A Case Study of Iranian EFL Learners. In The linguistic Journal, v. 1, n. 3: 110-126, 2006.

http://www.linguistics-journal.com/November_2006_fs\&sz.php Acesso: 24/04/2007.

SHOBEN, E. J. The representation of knowledge. In MCTEAR, M. (ed.). Understanding cognitive science. New York: Wiley, 1988, p. 102-119.

SOUZA, R. F. Atividades de compreensão oral para o ensino de LE mediado por computador: (re) pensando o desenho. In Simpósio Nacional de Letras e Linguística - SILEL, 12, 2009 e II Simpósio Internacional de Letras e Linguística, 2, 2009, Comunicação oral: Anais. Uberlândia, 2009.

SOUZA, R. F. Avaliação de softwares para o ensino de línguas: foco na compreensão oral. 2007. 111 f. Dissertação (Mestrado em Estudos Linguísticos). Belo Horizonte: Faculdade de Letras, Universidade Federal de Minas Gerais, 2007.

STEVENS, K. Can we improve reading by teaching background information? In Journal of Reading, 25: 326329, 1982, apud SADIGHI, F; ZARE, S. Is Listening Comprehension Influenced by the Background Knowledge of the Learners?: A Case Study of Iranian EFL Learners. In The linguistic Journal, v. 1, n. 3: 110-126, 2006.

http://www.linguistics-journal.com/November_2006_fs\&sz.php Acesso: 24/04/2007.

TALK TO ME, italiano. Montigny-le-Brettoneux (France): Auralog, (s.d.). 1 CD-ROM.

UN DERWOOD, M. Teaching Listening. 4. ed. New York: Longman, 1994.

WIDDOWSON, H. G. O ensino de línguas para a comunicação. Trad. José Carlos Paes de Almeida Filho. Campinas, SP: Pontes, 1991. 


\section{Apêndice A - Lista de checagem completa - SOUZA (2007)}

\section{Lista de checagem - Parte A}

1. O material oferece atividades específicas de $\mathrm{CO}$ ?

2. As atividades são estruturadas em pré-escuta, escuta e pós escuta?

3. Se presentes, as atividades de pré-escuta visam ativar esquemas e/ou antecipar elementos do texto relacionados ao texto-alvo (aspectos culturais, tema, participantes, estruturas ou funções linguísticas)?

4. Se presentes, as atividades de escuta visam guiar o aluno na compreensão do texto, ao invés de testar a sua compreensão?

5. Se presentes, as atividades de pós-escuta visam checar a compreensão dos estudantes, levantar, repetir e explicar os pontos problemáticos do texto e/ou ampliar conhecimentos sobre elementos da língua-alvo?

6. O material oferece atividades que tentam refletir objetivos de $\mathrm{CO}$ do mundo real?

7. As atividades apresentam instruções simples, claras e precisas?

8. Qual tipo de feedback automático as atividades fornecem durante a atividade de CO (genérico, situado, estratégico)?

9. O material apresenta atividades que trabalham estratégias de $\mathrm{CO}$ ?

10. O material apresenta atividades que informam, de alguma maneira, $\mathrm{o}$ aprendiz sobre as possíveis dificuldades de $\mathrm{CO}$ em língua estrangeira?

11. O material apresenta atividades que identificam, ressaltam e informam, de alguma maneira, as dificuldades de $\mathrm{CO}$ do aprendiz, de modo a conscientizá-lo das mesmas?

12. A atividade informa o aprendiz sobre - ou o incentiva a buscar em fontes externas - as estratégias que ele poderia utilizar para suprir suas próprias dificuldades de CO?

13. O material apresenta atividades de CO que utilizam vídeo?

14. Em caso de utilização de vídeo, as imagens condizem com o texto? As expressões faciais e corporais dos interlocutores condizem com o que está sendo dito?

15. Em caso de utilização de vídeo, o aluno é incentivado ou guiado a lançar mão das imagens e/ou expressões corporais e faciais dos interlocutores para construir sentido?

16. O material apresenta atividades de $\mathrm{CO}$ que ajudam o aprendiz a reconhecer funções comunicativas de sentenças, de acordo com situações, participantes e objetivos? 
17. O material oferece redundância de informações de elementos dos textos orais de base?

18. O material oferece atividades de $\mathrm{CO}$ que ajudam o aprendiz a reconhecer formas, dispositivos coesivos, padrões de acento, estrutura rítmica, contornos entonacionais da língua-alvo e os seus papéis na veiculação da informação?

19. O material oferece atividades de $\mathrm{CO}$ que ajudam o aprendiz a reconhecer sentido literal e implícito?

20. O material apresenta textos orais diversificados?

21. Qual tipo de atividades de $\mathrm{CO}$ o material apresenta: ascendente, descendente ou interativa?

22. O material oferece atividades que estimulam o aprendiz a buscar conhecimentos sobre a línguaalvo fora do software?

\section{Lista de checagem - Parte B}

1. O material oferece atividades de $\mathrm{CO}$ que exploram situações de interação face a face?

2. As atividades são estruturadas em pré-escuta, escuta e pós-escuta?

3. As atividades apresentam objetivos típicos desse contexto de interação face a face?

4. Nas atividades são trabalhadas estratégias de CO?

5. Nas atividades são trabalhadas possíveis dificuldades de CO específicas desse tipo de interação?

6. Os textos apresentados nas atividades reproduzem características típicas de discursos orais em interação face a face (velocidade típica, falsos começos, repetições, hesitações etc.)?

7. Nas atividades o aprendiz é incentivado e auxiliado a reconhecer funções comunicativas de sentenças, de acordo com situações, participantes e objetivos?

8. Nas atividades o aprendiz é incentivado e auxiliado a reconhecer sentido literal e implícito?

9. As atividades ajudam o aprendiz a reconhecer formas, dispositivos coesivos, padrões de acento, estrutura rítmica, contornos entonacionais do discurso oral em interações face a face e os seus papéis na veiculação da informação?

10. As atividades utilizam vídeo? As expressões corporais e faciais dos interlocutores condizem com o que está sendo dito?

11. Nas atividades o aprendiz é incentivado a lançar mão das expressões corporais e faciais dos interlocutores para construir sentido? 